\title{
INFECTIOUS DISEASES, NSW: DECEMBER 1999
}

\section{TRENDS}

Infectious disease notifications through the end of October are shown in Figure 4 and Table 5. Two cases of haemolytic uraemic syndrome in children were reported in October, one each from the Hunter and South Western Sydney areas. Investigations into risk factors for these cases are continuing.

While notifications were still down for arboviral infections in October, it is likely that notifications of the mosquito-borne Ross River and Barmah Forest virus infections will increase as Christmas approaches. Therefore, it is timely to remind people living in rural or bushland areas, and people who are travelling to these

\section{NSW PUBLIC HEALTH BULLETIN}

The NSW Public Health Bulletin is a publication of the NSW Department of Health. The editor is Dr Lynne Madden, Manager, Public Health Training and Development Unit, NSW Department of Health. Dr Michael Giffin is production manager.

The Bulletin aims to provide its readers with population health data and information to motivate effective public health action.

\section{Submission of articles}

Articles, news and comments should be 1000 words or less in length and include a summary of the key points to be made in the first paragraph. References should be set out in the Vancouver style, described in the New England Journal of Medicine, 1997; 336: 309-315. Send submitted articles on paper and in electronic form, either on disc (Word for Windows is preferred), or by email. The article must be accompanied by a letter signed by all authors. Full instructions for authors are available on request from the editor.

\section{Editorial correspondence}

Please address all correspondence and potential contributions to The Editor, NSW Public Health Bulletin, Locked Mail Bag 961, North Sydney NSW 2059 or to Lmadd@doh.health.nsw.gov.au. Tel (02) 9391 9956, Fax (02) 93919232.

\section{Distribution}

Please contact your local Public Health Unit or telephone (02) 93919942 to obtain copies of the NSW Public Health Bulletin or to notify us of a change of address. The Bulletin can be accessed via the Internet from the Department's Web site: www.health.nsw.gov.au/ public-health/phb/phb.html.

Back issues can be obtained from the Public Health Training and Development Unit, Locked Mail Bag 961, North Sydney NSW 2059. areas, to take special precautions to avoid mosquito bites, especially between now and the end of autumn. Now is the time to:

- check that your house is fully protected with functioning fly screens on all external doors and windows;

- get rid of containers of stagnant water around the house and garden where mosquitoes might breed;

- kill mosquitoes in your house with insect sprays, especially before going to bed;

- avoid exposing bare skin outdoors, especially around and after dusk and before dawn, or whenever mosquitoes are about; cover up with long sleeves and pants, and wear plenty of insect repellent.

Consecutive wet years are thought to increase the risk of more serious arboviral infections such as Murray Valley encephalitis, perhaps because the virus travels with birds from its usual domain in central Australia. The last outbreak of Murray Valley encephalitis in NSW occurred in 1974. Heeding the preceding advice about avoiding mosquito bites may be particularly important this summer should environmental conditions be favourable for Murray Valley encephalitis.

\section{NSW INFECTION CONTROL POLICY}

The NSW Department of Health recently released the Infection Control Policy Circular 99/87. This circular replaces the previous Infection Control Policy Circular 95/13. Circular 99/87 was prepared by the AIDS-Infectious Diseases Unit (AIDU) in consultation with key stakeholders in infection control including members of the Department's Infection Control Advisory Group and the Infection Control Practice Group. The policy is evidence-based and its requirements are consistent with international best practice. Changes in the new policy include:

- adopting Standard Precautions (replacing Universal Precautions);

- no longer requiring the routine use of bleach or sodium hypochlorite solutions in managing blood spills.

Since the release of the policy circular, the AIDU has received positive feedback from stakeholders who have embraced the document and its directives. Electronic copies of the policy can be downloaded from the Department's intranet site, and printed copies are available from the Better Health Centre at (02) 9816 0452. w 


\section{FIGURE 4}

REPORTS OF SELECTED INFECTIOUS DISEASES, NSW, JANUARY 1994 TO OCTOBER 1999, BY MONTH OF ONSET

These are preliminary data: case counts in recent months may increase because of reporting delays
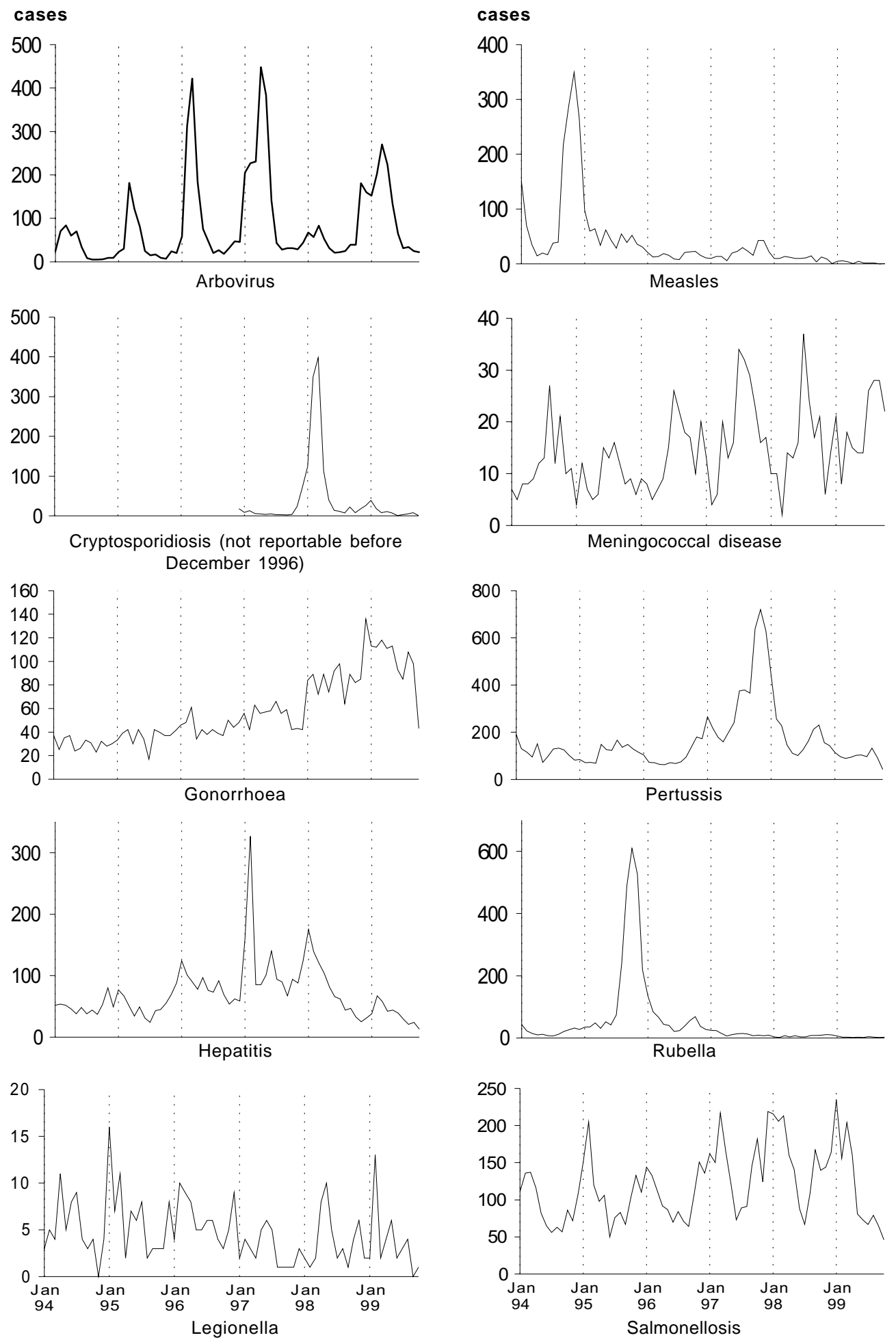


\section{Condition}

CSA NSA WSA WEN SWS CCA HUN ILL SES NRA

MNC NEA

\begin{tabular}{lllll|l|l|}
\multirow{2}{*}{ NEA MAC } & \multirow{2}{*}{ MNA } & \multirow{2}{*}{ FWA } & \multicolumn{2}{|c|}{ Total } \\
\cline { 5 - 6 } & & & for Octt & To date† \\
\hline
\end{tabular} AIDS

HIV infection*

Hepatitis B: acute viral*

Hepatitis C: acute

Hepatitis C: acute viral
Hepatis C: other $^{*}$

Hepatitis D: unspecified*

Hepatitis, acute viral (not otherwise specified)

Chancroid $^{*}$

Chlamydia (genital)*

Gonorrhoe

Vector-borne

Arboviral infection (BFV)*

Arboviral infection (RRV)

Arboviral infection (Other)

Malaria*

Zoonoses

Brucellosis*
Leptospirosis

Respiratory and othe

Blood lead level ${ }^{*}$
Legionnaires' Longbeachae

Legionnaires' Pneumophila*

Legionnaires' (Other)*

eprosy

Meningococcal infection (invasive)

Mycobacterial tuberculosis
Mycobacteria other than TB

Vaccine-preventable

$\begin{array}{rrrrrr}1 & - & - & 2 & - & 1 \\ - & - & - & \text { Reported } & \text { every two months } \\ - & 1 & - & - & - & - \\ 58 & 42 & 32 & 5 & 1 & - \\ - & - & - & 1 & - & - \\ 105 & 41 & 72 & 48 & - & 27 \\ - & - & - & - & - & - \\ - & - & - & - & - & - \\ - & - & - & - & - & - \\ 11 & - & 2 & 1 & 5 & 3 \\ 13 & 9 & 2 & 2 & 3 & 1 \\ 10 & - & 3 & 1 & 1 & - \\ \end{array}$

-
-
-
-
-
24
-
-
-
3
-
2

Adverse event after immunisation

$H$. influenzae b infection (invasive)

Measles

Mumps*

Pertussis

Rubella*

Faecal-oral

Botulism

Cholera*
Cryptosporidiosis*

Cryptosporidios
Giardiasis*

Food-borne illness (not otherwise specified)

Gastroenteritis (in an institution)

Haemolytic uraemic syndrome

Hepatitis $A^{*}$
Hepatitis $E^{*}$

isteriosis

Salmonellosis (not otherwise specified)

Typhoid and paratyphoid*

Verotoxin producing E. coli

* lab-confirmed cases only $\dagger$ includes cases with unknown postcode

SA $=$ Central Sydney Area

NSA = Northern Sydney Are 